Revista de la red interuniversitaria de estudios sobre las literaturas rioplatenses contemporáneas en Francia

$12 \mid 2015$

Prodigios borgeanos: ficciones, historias, teologías

\title{
Senderos que se bifurcan : dos manuscritos de un cuento de Borges
}

Daniel Balderston

\section{OpenEdition}

\section{Journals}

Edición electrónica

URL: http://journals.openedition.org/lirico/1992

DOI: $10.4000 /$ lirico.1992

ISSN: 2262-8339

Editor

Réseau interuniversitaire d'étude des littératures contemporaines du Río de la Plata

Referencia electrónica

Daniel Balderston, «Senderos que se bifurcan : dos manuscritos de un cuento de Borges », Cuadernos LIRICO [En línea], 12 I 2015, Publicado el 23 enero 2015, consultado el 10 diciembre 2020. URL : http:// journals.openedition.org/lirico/1992 ; DOI : https://doi.org/10.4000/lirico.1992

Este documento fue generado automáticamente el 10 diciembre 2020.

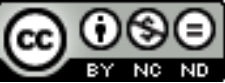

Cuadernos LIRICO está distribuido bajo una Licencia Creative Commons Atribución-NoComercialSinDerivar 4.0 Internacional. 


\title{
Senderos que se bifurcan: dos manuscritos de un cuento de Borges
}

\author{
Daniel Balderston
}

1 Desde hace cinco años que estoy trabajando en un libro sobre los manuscritos de Borges que se va a llamar How Borges Wrote. Inicialmente mi problema era la escasez de material : sólo un manuscrito se había publicado en edición facsimilar, el de «El Aleph» (después se publicaron tres más, una edición de los dos manuscritos de «Tlön», el de «El Sur », y anotaciones para una serie de conferencias sobre el budismo que tiene que ver con el librito Qué es el budismo) ; los manuscritos más importantes estaban en cajas fuertes o a la venta por centenares de miles de dólares; y no tenía idea de dónde estaban las cosas. Ahora mi problema es el opuesto: tengo fotocopias o fotografías de centenares de manuscritos (incluyendo más o menos la mitad de los textos que constituyen los libros Discusión, Historia universal de la infamia, Ficciones, El Aleph y Otras inquisiciones); los coleccionistas y los anticuarios me han dejado mirar materiales que saben que no voy a robar, ni comprar tampoco; y conozco tan bien los procedimientos de Borges como escritor que reconozco un auténtico papel de trabajo en un instante y lo puedo diferenciar de una copia en limpio que hizo el autor -o, en el peor de los casos, un falsificador -. Aquí voy a discutir un caso que me parece especialmente significativo, de dos manuscritos de «El jardín de senderos que se bifurcan », el cuento de 1941 que da título al libro publicado el último día de ese año y que tres años después pasará a formar la primera parte del libro Ficciones ${ }^{1}$.

De este cuento tengo fotocopias parciales de una primera versión (falta el inicio del cuento) y en un catálogo de subasta hay imágenes de una segunda. Conozco otros dos casos de cuentos que existen en dos versiones manuscritas, una que son los papeles de trabajo propiamente dichos con muchas variantes y posibilidades y otra que es una versión más cercana a una copia en limpio : «Las ruinas circulares » $\mathrm{y}$ « Tlön ». En este caso, la fotocopia que tengo es una copia de una copia, y no sé dónde está el original ; en el caso del catálogo, el manuscrito no se vendió en la subasta y no sé quién lo tiene. Pero 
la identidad de los dueños no me importa y los detalles de los manuscritos sí, por lo tanto voy a describir en detalle qué es lo que hay.

3 El manuscrito incompleto debe haberse escrito en un cuaderno Lanceros Argentinos de 1910 (una marca de cuadernos que Borges utiliza en otras ocasiones), porque la carpeta de fotocopias a la que tuve acceso incluye la fotocopia de la portada y la contraportada de un cuaderno de ese tipo. Consta de una serie de páginas numeradas : 3, 5, 6, 7, 8, 9, 10, 11, 12 y 13. En la página 13 termina el cuento, pero lo hace a modo de inserción que está cabeza abajo en el margen superior de la hoja, donde después de un círculo negro (Borges usaba símbolos geométricos para marcar inserciones) podemos leer : "Sabe que mi problema era indicar (a través del estrépito de la guerra) la ciudad francesa de Albert y que no hallé otro \{método que matar a / medio que asesinar a\} alguien que llevara ese nombre. No sabe (nadie puede saber) lo mucho que... " (y termina con esos puntos suspensivos, es decir que falta « mi innumerable contrición y cansancio »). Como se habrán dado cuenta, faltan las primeras dos hojas del manuscrito y la cuarta ; a esto volveré.

El manuscrito que aparece en el catálogo Travel, Literature, Autographs and Fine Books de Bloomsbury Auctions, para una subasta que se llevó a cabo el miércoles 23 de junio de 2010 sin que nadie ofreciera la suma mínima que el catálogo dice que vale el manuscrito (de doscientos a trescientos mil dólares) consta de 12 páginas de un cuaderno Haber con un manuscrito completo del cuento en una versión ya cercana a la publicada. La primera hoja, con el título «El Jardín de senderos que se bifurcan » (con « jardín » en mayúscula), arranca con la información correcta : «En la página 252 de la Historia de la Guerra Europea de Liddell Hart»-los lectores recordarán la errata que ha recorrido casi todas las ediciones de Borges, en que esa página 252 se transforma en la página 22 o 242- y termina, después de "mi innumerable contrición y cansancio", con una comilla que marca todo el texto, a partir del segundo párrafo, como una cita (detalle que desaparece en las versiones publicadas) y con la firma «Jorge Luis Borges » y su rúbrica. (La primera y la última hoja se reproducen en tamaño tres veces más grande que las otras, así que las dos imágenes están bastante pixeladas, pero mucho menos que las otras diez páginas). Borges solía firmar sus manuscritos cuando los copiaba en limpio como regalos, y este manuscrito es claramente una copia en limpio, aunque tiene inserciones y correcciones (por ejemplo, la « Nota del Editor » sobre el « asesinato » de Hans Rabener alias Walter Runeberg es una inserción en el margen izquierdo). El cuento va dedicado a Victoria Ocampo, entonces me imagino por dos casos paralelos -el manuscrito de «El Aleph» dedicado y regalado a Estela Canto, y el dactiloscrito de «Emma Zunz» dedicado y regalado a Cecilia Ingenieros- que en algún momento este manuscrito habría pertenecido a la fundadora de Sur (donde Borges publica el libro el 31 de diciembre de 1941).

5 «Faltan las dos páginas iniciales », nos dice el final del primer párrafo de este segundo manuscrito. El resto es fácil de leer porque es el texto que conocemos de las Obras completas, aunque se puede ver que la imagen está muy pixelada cuando la amplío (por tratarse de una imagen en baja resolución, que es la desgracia de estos catálogos, supongo que por un prurito de no regalar imágenes buenas a los no compradores como nosotros). Dice así :

En la página 252 de la Historia de la Guerra Europea de Liddell Hart, se lee que una ofensiva de trece divisiones británicas (y apoyada por mil cuatrocientas piezas de artillería) contra la línea Serre-Montauban había sido planeada para el veinticuatro de julio de 1916 y debió postergarse hasta la mañana del día veintinueve. La siguiente declaración, dictada, releída y firmada por el doctor Yu Tsun, antiguo catedrático 
de inglés en la Hochschule de Tsingtao, arroja una insospechada luz sobre el caso.

Faltan las dos páginas iniciales.

6 Esto es lo que podemos leer, por ejemplo, en las mal llamadas Obras completas de 1974, salvo que la página 252 se transforma en 242 ; el error inicial de escribir el mes de julio en vez de junio (la batalla del Somme comenzó el primero de julio pero los bombardeos comenzaron el 24 de junio) está en el manuscrito y en la versión de 1974. Lo que falta en el manuscrito del primer párrafo de la versión publicada es la cita de Liddell Hart : « Las lluvias torrenciales (anota el capitán Liddell Hart) provocaron esa demora -nada significativa, por cierto - » (Obras completas: 472), pero en ese punto del manuscrito aparece un círculo negro que lleva precisamente a esa inserción, cabeza abajo en el margen superior.

7 «Faltan las dos páginas iniciales »: ¿será que cuando Borges copia el cuento del primer cuaderno al segundo, esas dos hojas le faltan? ¿o que las hizo desaparecer ? Sabemos por el manuscrito de «La casa de Asterión » que está en la Biblioteca Small de la Universidad de Virginia, y por el de «La lotería en Babilonia » que está en la biblioteca pública de Nueva York (y he visto muchos otros casos de esto) que Borges a veces cortaba las hojas de sus cuadernos para quitar errores, pero de todas maneras es llamativa la coincidencia entre la ausencia de las primeras dos hojas del primer manuscrito y el final del primer párrafo del segundo. Si uno comienza a fijarse, hay muchas descripciones de manuscritos en los textos de Borges, y muchas de ellas pueden entenderse como descripciones de sus propios manuscritos : veremos un caso de una mise en abîme en el primer manuscrito un poco más adelante.

8 El primer manuscrito comienza in medias res en la tercera página con las palabras « peligro de ser reconocido; el hecho es que en la calle me sentía visible y vulnerable, in desierta me sentía visible y vulne rable $^{2}$, infinitamente ", es decir, en la mitad del tercer párrafo del cuento publicado (Obras completas : 474). Faltan, entonces, la nota inicial del editor sobre la «declaración, dictada releída y firmada » por Yu Tsun, falta la primera nota, y falta toda la autofiguración inicial de Yu Tsun como autor del documento: su relación con Runeberg, el miedo que le tiene al capitán Madden, el jardín simétrico de Hai Feng, el padre muerto, el problema de hacer llegar un mensaje a Berlín, y la declaración (que como mostré hace años es un inesperado eco de la declaración del patriota irlandés Padraic Pearse en el juicio militar en Dublín) que comienza : « No lo hice por Alemania, no. [...] Lo hice, porque sentía que el Jefe tenía en poco a los de mi raza- a los innumerables antepasados que confluyen en mí » (Obras completas : 473). Todo eso está en el segundo manuscrito; me intrigaría saber si en el primero Borges puso sus fichas de lecturas, como a veces hace en sus papeles de trabajo, y así confirmar si consultó alguna versión de la declaración de Padraic Pearse, pero eso no puede hacerse en ausencia de las hojas. (De todas maneras lo que queda del primer manuscrito no tiene ese tipo de anotaciones bibliográficas, que suelen aparecer en el margen izquierdo en los papeles de trabajo de Borges).

9 Voy a saltar ahora a la página 5 del primer manuscrito, para ver un típico detalle de este manuscrito. Seguiré las siguientes convenciones: para palabras tachadas usaré la tachadura que nos ofrece Microsoft Word: tachadura. Para inserciones que aparecen como interlineados, usaré el interlineado. Para alternativas que se ponen una al lado de la otra (o de las otras), usaré la raya /. [Mis interpolaciones o comentarios aparecen entre corchetes.] La parte que me interesa es la descripción del jardín de Stephen Albert : 
es un laberinto de laberintos, es un sinuoso laberinto creciente que abarcara (todo) el pasado y (todo) el porvenir y q. \{implicara / enredara de algún modo los astros. / no excluyera los astros. Absorto en esas \{ilusorias / engañosas\} imágenes, olvidé mi destino (miserable) de perseguido. Me sentí, por unos instantes un tiempo indeterminado, percibidor abstracto del mundo. La tarde, el vago y vivo campo, la luna, obraron en

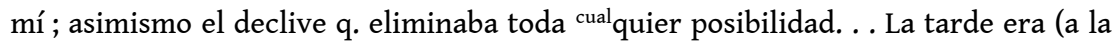
vez) infinita e íntima.

posibilidad de cansancio ${ }^{3}$. El camino bajaba y se bifurcaba, entre ya confusos jardines las ya confusas praderas. Una música aguda y monosilábica como silábica se aproximaba y se alejaba en el vaivén del viento, empañada de hojas y de distancia. Pensé que un hombre puede ser enemigo de otros hombres, de otros momentos de otros hombres, pero no de un país: no de luciérnagas, palabras, robles, ocasos. Llegué así, a una aguas, ponientes. jardines' cursos de agua, ponientes. especie de pabellón. Comprendí, de pronto, dos cosas, la primera trivial, la segunda casi increíble : la música venía del pabellón, la música era china.

En los papeles de Borges, siempre vale la pena notar qué se escribe de una vez para siempre y qué se reescribe obsesivamente. Podemos recordar dos casos ejemplares : las 22 palabras que se ensayan para escoger dos en el manuscrito del poema « A Francisco López Merino" (que analicé en el número 246 de la Revista Iberoamericana) y la obsesiva reescritura de la última cláusula de «La muralla y los libros », la definición del « hecho estético ». En este caso los detalles con los que trabaja de forma obsesiva son: 1) la relación entre el destino humano y los astros (si estos están "implicados », " enredados » o «no excluidos » de ese destino), 2) si Yu Tsun queda pasmado «por unos instantes" o por « un tiempo indeterminado », 3) si es una música « monosilábica » o « casi silábica », y 4) la descripción de lo que importa para definir un país, que es una colección de luciérnagas, palabras, y luego « aguas, ponientes » 0 « robles, ocasos » 0 « jardines, cursos de agua, ponientes ». Como suele ser el caso, la solución a estas dudas no está dada en este manuscrito pero en el segundo sí: escoge "implicar », " un tiempo indeterminado », « casi silábica " y la serie larga « luciérnagas, palabras, jardines, cursos de agua, ponientes » . Es decir, le interesa hacer que Yu Tsun perciba su destino en las cosas de este mundo, y que su descubrimiento de un tiempo multifacético y en múltiples planos se dé en el tiempo de su relato. En cambio, la descripción del laberinto de laberintos, la instrucción de volver siempre a la izquierda, el hecho de que la música fuera china : todo eso ya está dado antes de que la pluma comience a rasgar el papel. De estos detalles me parece particularmente interesante la vacilación entre música " monosilábica » $\mathrm{y}$ " casi silábica » : la extrañeza que produce la lengua china o la música china no es porque sean extrañas en sí mismas sino porque son extrañas en ese lugar: el monosilabismo del chino es distinto al monosilabismo del inglés, y Borges quiere que Yu Tsun registre por un momento su asombro ante las características de cada lengua, cada música, cada país (el tema, claro, de la frase en cuestión).

11 Ahora vamos a pasar a confrontar las versiones del final del relato. Primero, sólo para que se tenga una referencia visual, muestro la última página del primer manuscrito, con la inserción del final de la confesión de Yu Tsun arriba, cabeza abajo, y la última página de la segunda versión, la firmada y rubricada, con unas pocas correcciones. Lo que me interesa, sin embargo, no es el último párrafo sino el penúltimo. En la primera versión leemos :

Albert se levantó. \{Abrió el cajón del alto secretario ; me dio por un instante / \{Alto, abrió el cajón del alto secretario; me dió por un momento la espalda. Ya había preparado el revólver. \{Con mano cuidadosa hice fuego : Albert / \{Disparé con sumo cuidado : Albert murió sin una queja, \{en seguida. / inmediatamente. \} Yo juro que su muerte fue instantánea : una fulminación. 
12 En la segunda versión leemos (ya con dificultad por la pixelación, pero mejor con el catálogo original y una lupa) :

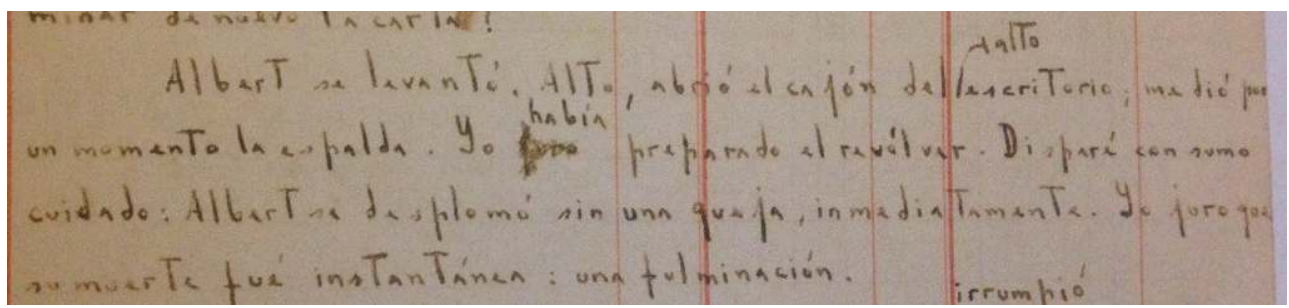

Albert se levantó. Alto, abrió el cajón del alto escritorio, me dio por un momento la espalda. Yo tenía había preparado el revólver. Disparé con sumo cuidado. Albert se desplomó sin una queja, inmediatamente. Yo juro que su muerte fue instantánea : una fulminación.

Aquí la duda importante es si repetir el adjetivo « alto »: en la primera versión ya había dicho que Albert era «alto» y el «secretario ( (después «escritorio») también. En la segunda versión, por la superstición de la no repetición de palabras en la prosa de lengua española (una superstición que Borges viola con una enorme frecuencia) duda si no repetir y luego resuelve repetir. Es importante la comparación implícita, que se logra por la repetición del adjetivo, entre Albert y el mueble del antepasado de Yu Tsun. Copia su texto borrando la repetición y luego inserta de nuevo el adjetivo, y publica la versión con la repetición de « alto».

El otro ejemplo que discutiré brevemente antes de terminar es la descripción que hace Stephen Albert del tiempo intrincado de la novela. En el primer manuscrito ya tenemos idea de la novela como adivinanza :

He restablecido el orden de esa \{obra / novela, he corregido infatigable los errores que la ignorancia / negligencia de los copistas ha deslizado / introducido, la he traducido cuidadosamente al inglés / vertido (casi) literalmente [al inglés] -aquí están las pruebas de páginas; le aseguro / juro que no emplea una sola vez la palabra tiempo. He confrontado centenares de manuscritos, he adivinado / conjeturado el plan de ese caos, he restablecido, he creído restablecer, el orden auténtico / primordial, he traducido la obra entera: le juro / me consta q. no emplea una sola vez la palabra tiempo.\}

La versión publicada de esto dice :

He confrontado centenares de manuscritos, he corregido los errores que la negligencia de los copistas ha introducido, he conjeturado el plan de ese caos, he restablecido, he creído restablecer, el orden primordial, he traducido la obra entera : me consta que no emplea una sola vez la palabra tiempo. La explicación es obvia: El jardín de senderos que se bifurcan es una imagen incompleta, pero no falsa, del universo tal como lo concebía Ts'ui Pên. A diferencia de Newton y de Schopenhauer, su antepasado no creía en un tiempo uniforme, absoluto. Creía en infinitas series de tiempos, en una red creciente y vertiginosa de tiempos divergentes y paralelos. Esa trama de tiempos que se aproximan, se bifurcan, se cortan o que secularmente se ignoran, abarca todas las posibilidades. (Obras completas : 479)

Como se puede apreciar ahora, esta descripción es bastante aguda del primer manuscrito, mucho más que del segundo: cuando Borges escribe sus primeras versiones suele suspender por un momento la ansiedad por la versión que va a escoger, y deja coexistir o "pulular» las posibilidades (como percibe Yu Tsun en dos notables instancias en la acción de este relato). En cambio, cuando copia en limpio y firma y rubrica ya se ha 
decidido por una de las muchas posibilidades, aunque el texto hable de la posibilidad contraria, de no escoger.

Mi último ejemplo será de esa misma índole. Recordarán el último diálogo entre Yu Tsun y Stephen Albert, que terminará con la llegada del capitán Richard Madden y la necesidad que se le impone a Yu Tsun de matar a su admirado maestro :

[-... o existimos en la mayoría de esos tiempos : en algunos existe usted y no yo ; en otros, yo, no usted; en otros, los dos. En éste, que un favorable azar me depara, usted ha llegado a mi casa ; en otro, usted, al atravesar el jardín, me ha encontrado muerto ; en otro, yo digo estas mismas palabras, pero soy un error, un fantasma.

-En todos, -articulé no sin un temblor - yo agradezco y venero su recreación del jardín de Ts'ui Pên.

-No en todos -murmuró con una sonrisa. El tiempo se bifurca perpetuamente hacia innumerables futuros. En uno de ellos soy su enemigo.

Volví a sentir esa pululación de que hablé. Me pareció que el húmedo jardín que rodeaba la casa estaba saturado hasta lo infinito de invisibles personas. Esas personas eran Albert y yo, secretos, atareados y multiformes en otras dimensiones del tiempo. [...]

El porvenir ya existe -respondí- pero yo soy su amigo. ¿Puedo examinar de nuevo la carta?

Albert se levantó. Alto, abrió el cajón del alto escritorio [...] (Obras completas: 479-480)

En el primer manuscrito esa « pululación » está bellamente presentada en la página :

Esa trama de tiempos q. se bifurcan agota todas las posibilidades. En algunos existe $\mathrm{Vd}$. ; en otros, yo ; en otros, los dos. / Vd. y no yo ; en otros, yo, no Vd. ; en otros, los dos. No existimos en la mayoría de esos tiempos ; en algunos ... [existe Vd. etc.]. En éste, que un favorable azar me depara, Vd. ha llegado a mi casa; en otros, Vd. al entrar, me ha encontrado muerto ; en otro, yo digo estas mismas palabras, pero soy un espectro. / fantasma. / error, un fantasma.

La fascinación que siente Albert por el manuscrito de Ts'ui Pên, y que Yu Tsun siente cuando se lo describe, es por la posibilidad de la coexistencia de los muchos mundos, una anticipación por parte de Borges de la « Everett Hypothesis » en la física cuántica en unos quince años, como ha demostrado Alberto Rojo (y que también comentaron en su momento Nicholas Rescher y Floyd Merrell). Lo fascinante de este detalle del manuscrito es que se ve en la hoja esa "pululación » de posibilidades: Borges escribe desde la incertidumbre radical, y sobre la incertidumbre radical. El proceso de escritura de « El jardín de senderos que se bifurcan" lleva a cabo el proceso de bifurcación y simultaneidad del que habla el cuento.

Rojo, Alberto. Borges y la física cuántica. Buenos Aires : Siglo XXI, 2013.

\section{BIBLIOGRAFÍA}

Balderston, Daniel. « Borges y sus precursores ». Itinerarios 14 (2011) : 113-120.

Balderston, Daniel. «"Demasiado evanescente y extático" : reflexión sobre unas anotaciones de Borges en un ejemplar de las Noches áticas de Aulo Gellio ». Variaciones Borges 37 (2014) : 69-79. 
Balderston, Daniel. « Detalles circunstanciales : sobre dos borradores de "El escritor argentino y la tradición" ». La Biblioteca 13 (2013) : 32-45.

Balderston, Daniel. « Detalles circunstanciales : sobre dos borradores de "El escritor argentino y la tradición" ». Cuadernos LIRICO 9 (2013) http://lirico.revues.org/1111

Balderston, Daniel. « "His insect-like handwriting": Marginalia and Commentaries on Borges and Menard ». Variaciones Borges 31 (2010) : 125-136.

Balderston, Daniel. «Liminares : sobre el manuscrito de "El hombre en el umbral" ». Hispamérica 122 (2012) : 28-36.

Balderston, Daniel. « Los manuscritos de Borges : "Imaginar una realidad más compleja" ». Variaciones Borges 28 (2009) : 15-24.

Balderston, Daniel. « Los manuscritos de Borges : "Imaginar una realidad más compleja que la declarada al lector" ». Cuadernos LIRICO 7 (2012).

Balderston, Daniel. « Lo marginal es lo más bello ». Jornadas Internacionales « Borges lector » en la Biblioteca Nacional. Buenos Aires : Biblioteca Nacional, 2013, pp. 7-15.

Balderston, Daniel. « Palabras rechazadas : Borges y la tachadura ». Revista Iberoamericana 246 (2014) : 81-93.

Balderston, Daniel. « "Puntos suspensivos" : sobre o manuscrito de "Hombre de la esquina rosada" ». Manuscrítica 24 (2013) : 7-14.

Balderston, Daniel. « "Su letra de insecto" : Reflexiones sobre los manuscritos de Borges y Menard ». En : Magdalena Cámpora y Javier Roberto González (Ed.). Borges-Francia. Buenos Aires: Universidad Católica Argentina, 2011, pp. 509-514.

Balderston, Daniel. « The Theory of Games and Genetic Criticism: On the Manuscript of "La lotería en Babilonia" ». Variaciones Borges 36 (2013): 155-165.

Balderston, Daniel. «"The Universe in a Nutshell: The Long Sentence in 'El Aleph" ». Variaciones Borges 33 (2012) : 53-72.

Borges, Jorge Luis. «El jardín de senderos que se bifurcan ». Manuscrito en Cuaderno Avon. Borges, Jorge Luis. « El jardín de senderos que se bifurcan ». Manuscrito en Cuaderno Haber reproducido en Travel, Literature, Autographs and Fine Books. Catálogo de una subasta en Nueva York el 23 de junio de 2010. Londres: Dreweatts/Bloomsbury, 2010.

Borges, Jorge Luis. Obras completas. Buenos Aires: Emecé, 1974.

Merrell, Floyd. Unthinking Thinking: Jorge Luis Borges, Mathematics and the New Physics. West Lafayette: Purdue University Press, 1991.

Rescher, Nicholas. The Primacy of Practice: Essays Towards a Pragmatically Kantian Theory of Empirical Knowledge. Oxford : Basil Blackwell, 1973.

\section{NOTAS}

1. La larga lista de mis artículos sobre manuscritos de Borges aparece en las obras citadas. Esos artículos se pueden encontrar en la sección de crítica de la página del Centro Borges ( www.borges.pitt.edu ) y en la página d-scholarship.pitt.edu de la biblioteca de mi universidad.

2. La palabra « vulnerable » comienza así, en interlineado, y luego sigue en el cuerpo del texto, ya que antes había escrito la misma palabra, y la había tachado. 
3. Los puntos suspensivos indican que Borges pensaba en alternativas a " posibilidad ", que en el renglón siguiente se resuelve con « posibilidad de cansancio ».

\section{RESÚMENES}

Este artículo es un análisis de dos manuscritos del cuento de Borges « El jardín de senderos que se bifurcan", publicado por primera vez en el libro del mismo título en 1941. Un manuscrito contiene muchísimas variantes y posibilidades, acorde con el tema del cuento ; el segundo es una copia en limpio, pero también en ese texto existen variantes y posibilidades.

Cet article analyse deux manuscrits de la nouvelle de Borges «El jardín de senderos que se bifurcan ", publiée pour la première fois dans le livre du même titre en 1941. Un des manuscrits contient de nombreuses variantes, en accord avec le thème de la nouvelle ; l'autre est une copie au propre, mais elle présente aussi des variantes et des possibilités différentes.

This article analyzes two manuscripts of Borges's story "The Garden of Forking Paths ", published for the first time in the book of the same name in 1941. One manuscript consists of numerous variants and possibilities, in keeping with the theme of the story; the other is a clean copy, but it also includes some variants and possibilities.

\section{ÍNDICE}

Mots-clés: Borges, «El jardín de senderos que se bifurcan », manuscrits, variantes, possibilités

Keywords: manuscripts, variants, possibilities

Palabras claves: manuscritos, posibilidades

\section{AUTOR}

\section{DANIEL BALDERSTON}

University of Pittsburgh

dbalder@pitt.edu 